Document downloaded from:

http://hdl.handle.net/10251/67436

This paper must be cited as:

Payri, R.; Salvador Rubio, FJ.; Gimeno, J.; Bracho Leon, G. (2011). The effect of temperature and pressure on thermodynamic properties of diesel and biodiesel fuels. Fuel. 90(3):1172-1180. doi:10.1016/j.fuel.2010.11.015.

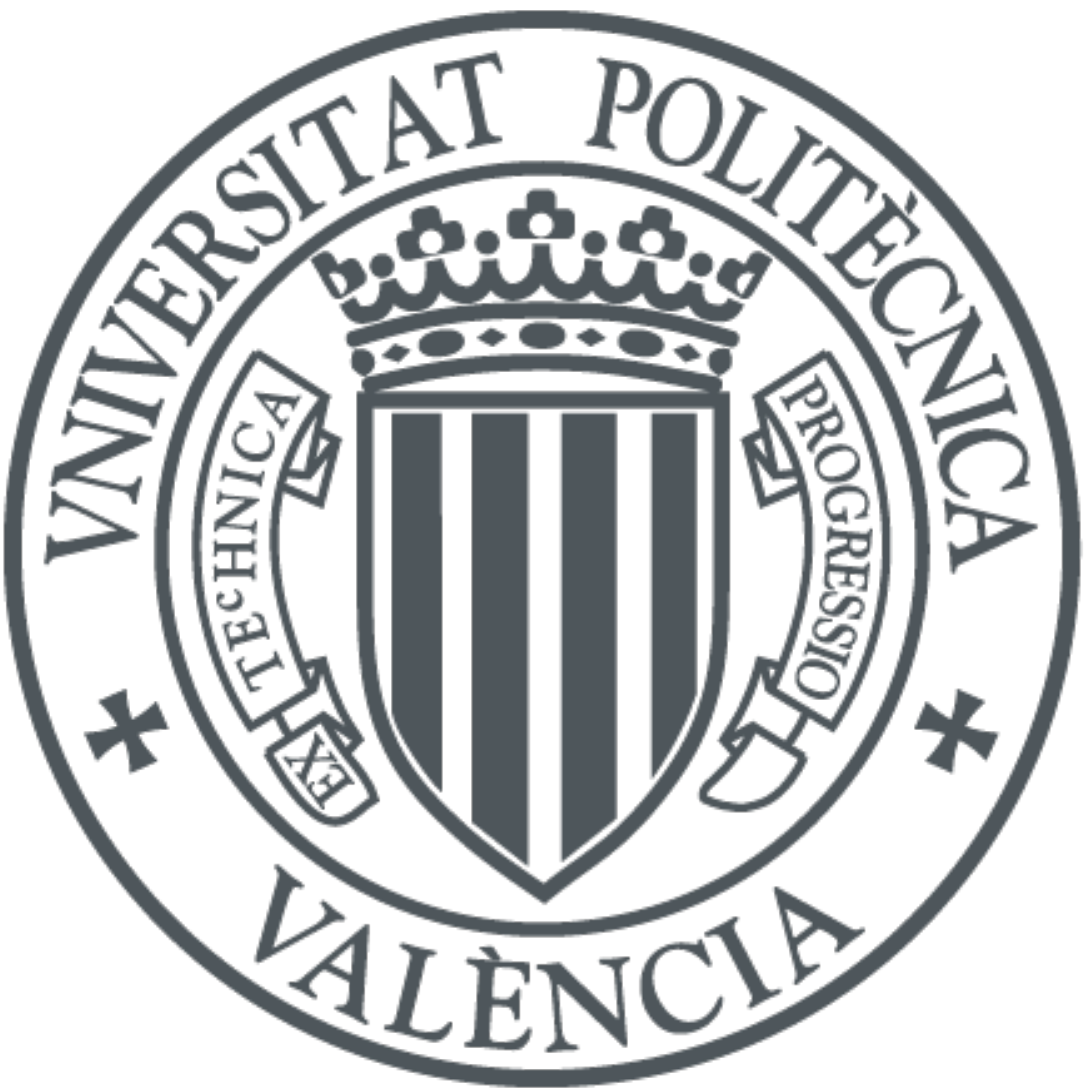

The final publication is available at

http://dx.doi.org/10.1016/j.fuel.2010.11.015

Copyright Elsevier

Additional Information 


\title{
THE EFFECT OF TEMPERATURE AND PRESSURE ON THERMODYNAMIC PROPERTIES OF DIESEL AND BIODIESEL FUELS
}

\author{
Payri R*, Salvador FJ, Gimeno J, Bracho G \\ CMT-Motores Térmicos, Universidad Politécnica de Valencia \\ Camino de Vera s/n, E-46022 Valencia, Spain. \\ ${ }^{*}$ Corresponding author. Tel.; +34 963879658; Fax: +34 963877659. E-mail \\ address: rpayri@mot.upv.es (R.Payri).
}

\begin{abstract}
The current work focuses on the study of the influence of pressure and temperature on three important thermodynamic properties: speed of sound, compressibility and density of common diesel fuels. The sample fuels studied were conventional diesel (Repsol Elite), Rape Methyl Ester (typical bio-diesel used in Spain) and a fuel used especially for winter season (Arctic). Speed of sound and densities have been determined experimentally. The third property, Bulk Modulus, has been calculated from the other two. Speed of sound measurements have been carried out in wide range of temperatures $(298<T / K$ $<343)$ and pressures $(15<p / \mathrm{MPa}<180)$, which represent the typical values used in injection systems for diesel engines. Hence, a particular configuration was coupled to the high-pressure injection system, obtaining accurate
\end{abstract}


measurements at these extreme conditions. A detailed description of the method is presented; also, the obtained results are listed, with an uncertainty of $\sim 0.3 \%$. Density measurements have been performed over a broad range of temperatures $(298<T / K<343)$, using two commercial devices, obtaining an overall uncertainty of $\sim 0.6 \%$.

Keywords: Fuel Properties, Diesel, Biofuel, Speed of Sound, Density.

\section{Nomenclature}

$\begin{array}{ll}a & \text { Speed of Sound } \\ B_{S} & \text { Isentropic Bulk Modulus } \\ B_{T} & \text { Isothermal Bulk Modulus } \\ C_{p} & \text { Isobaric Heat Capacity } \\ C_{v} & \text { Isochoric Heat Capacity } \\ L & \text { Longitude } \\ p & \text { Pressure } \\ p_{a t m} & \text { Atmospheric pressure } \\ p_{o} & \text { Pressure at the initial point } \\ T & \text { Temperature } \\ T_{o} & \text { Temperature at reference point } \\ t_{s} & \text { Time }\end{array}$

$\alpha \quad$ Isobaric coefficient of thermal expansion 
$\alpha_{t} \quad$ Thermal coefficient of the pipe material

$\beta_{t} \quad$ Compressibility coefficient of the pipe material

$\rho \quad$ Fluid Density

\section{Abbreviations:}

ARCT Arctic Fuel

REF Reference fuel

RME Rape Methyl Ester

\section{Introduction}

In diesel engines, differences in physical properties of fuels could change the injection mechanism, the fuel spray behavior, the combustion performance and consequently have an effect on pollutant emissions ([1]). Nowadays, many types of diesel fuels have been developed, the major part of them were intended for reduce emissions, fossil fuel dependency and costs, such as biodiesels and synthetic fuels; and other ones have been developed for better performance at a given conditions, such as winter fuels, etc. In any case, all of them will have their own composition and physical properties, altering the engine functionality.

In the past, many researchers have identified the physical properties that could affect the system injection performance. Generally, some of those properties that influence the injection are density, speed of sound and isentropic bulk modulus ([2],[3],[4],[5]). 
Concerning the density influence, results reported by ([6],[7]) concluded that fuels with higher density have little higher mass flow rate for the same injection conditions, so, the mass quantity in the combustion chamber would be higher. This was confirmed later by Luján J.M. et al. ([8],[9]). Besides, Van Gerpen et al. ([2]) noted the influence of bulk modulus, which affects the speed of sound on diesel injection systems; they suggested that using biodiesel with higher bulk modulus could increase the NOx values due mainly to an advance of the start of injection time (applicable only to pump-line-injector type systems); this happened because high bulk modulus of compressibility is associated to higher speed of sound values, leading in faster propagation of pressure waves from the pump to the injector needle, and thus an earlier needle lift. This assumption is not valid to common-rail systems, because the opening and closing mechanisms are different. Nevertheless, the bulk modulus and speed of sound values are indispensable parameters for system modeling ([10]) and for experimental injection rate determination ([4],[11]).

On the other hand, all the fluid properties mentioned before depend on other important variables such as pressure and temperature. In a real diesel engine the operating points involve strong pressure fluctuations and a wide range of temperatures, so it is expected that the fluid properties could change in terms of these two variables. The accuracy of the injection modeling is especially affected by the elasticity of the fuel ([5]), indeed some authors proved that model results are different assuming it not dependent on pressure. Therefore, is necessary to understand the behavior of those properties in real diesel engine conditions. Various researchers have recognized this dependency of fuel 
properties with pressure and temperature ([12],[13]), and have performed some works in order to quantify their relation. However, technological restrictions have limited the maximum values reached for the measurements of fuel properties, and typical high pressures and temperatures involved in injection processes have been very hard to achieve. Previous works have reported the tendency of some of these properties against the pressure up to $35 \mathrm{MPa}$ ([2],[3]), others have reached $60 \mathrm{MPa}([12],[14])$, or $150 \mathrm{MPa}$ ([15]), etc. using different liquids as alkanes, petroleum diesels or biodiesel. Nevertheless, actual diesel commonrail systems can reach higher pressures than those pressures reported in previous papers, and fuel diversity is increasing, then it is necessary to extend these data to higher pressure limits and to other fuels commonly used on commercial diesel engines and for research purposes.

Hence, the aim of this paper is to present a data base with values of bulk modulus, density and speed of sound at different pressure values, from $15 \mathrm{MPa}$ up to $180 \mathrm{Mpa}$, and several temperatures, from $298 \mathrm{~K}$ up to $343 \mathrm{~K}$, of three fuel samples, Rape Methyl Ester (typical bio-diesel used in Spain RME), one fuel used especially for winter season (ARCT), and a conventional fuel delivered by Repsol (Elite fuel) used as reference. Speed of sound values are obtained experimentally, using a special methodology designed for that purpose. Density has been measured using two commercial devices at atmospheric pressure. Afterwards, suitable procedure to estimate density and bulk modulus values at high pressure based on theoretical approaches is presented. Finally, mathematical correlations of the fuel properties in dependence on pressure and temperature are listed. 


\section{Theoretical Basis}

For pure liquids and mixtures, it has been demonstrated that a powerful tool that provides helpful information of thermodynamic properties is the speed of sound measurement ([16],[17]). In general, in thermo-fluidynamic systems the speed of sound of a fluid delimits the pressure wave movement from one position to another in a flow at a given condition. In pipe systems the simplest approach to tracking wave propagation is to assume a disturbance with small amplitude (compared with that of the undisturbed flow), which travels from one given point to another, as it is shown in Figure 1. In such case, the propagation of the disturbance phenomena, through the homogeneous medium, will travel at a single wave speed $a$ and could be considered independent of either the wave form or the direction of propagation ([18]); for acoustic waves a represents the speed of sound and it can be obtained from Equation 1:

$$
a=\frac{L}{t_{s}}
$$

where $L$ represents a longitude and $t_{s}$ is the time required for the wave to transverse the length $L$. This definition is represented in Figure 1 .

Moreover, another expression associated with the speed of sound is Equation 2:

$$
a^{2}=\frac{B_{S}}{\rho}
$$


where $B_{S}$ is the isentropic bulk modulus and $\rho$ is the density of the fluid ([19]). Also, the isentropic bulk modulus $B_{S}$ and the isothermal bulk modulus $B_{T}$ can be defined as:

$$
\begin{aligned}
& B_{S}=\rho\left(\frac{\partial p}{\partial \rho}\right)_{S} \\
& B_{T}=\rho\left(\frac{\partial p}{\partial \rho}\right)_{T}
\end{aligned}
$$

where $p$ is the pressure. In general terms, $B_{T}$ and $B_{S}$ are connected as states Equation 5:

$$
\frac{1}{B_{T}}=\frac{1}{B_{S}}+\frac{T \alpha^{2}}{\rho C_{p}}
$$

in which $\alpha$ designates the isobaric coefficient of thermal expansion and $C_{p}$ the isobaric heat capacity. Combining Equations 2, 3, 4 and 5 a general expression is obtained:

$$
\left(\frac{\partial \rho}{\partial p}\right)_{T}=\frac{1}{a^{2}}+\frac{T \alpha^{2}}{C_{p}}
$$

Solving the Equation 6 for an isothermal line, a relationship is obtained which explicitly links density to the speed of sound:

$$
\rho(p, T)=\rho\left(p_{o}, T\right)+\int_{p_{o}}^{p} \frac{d p}{a^{2}}+T \int_{p_{o}}^{p}\left(\frac{\alpha^{2}}{C_{p}}\right) d p
$$

In the right side of last expression, the first term provides the main contribution and can be obtained directly measuring the density at atmospheric pressure. The second term corresponds to the predominant additive contribution, and could be evaluated directly by means of the speed of sound along the isotherms 
considered. The last term numerically only represents a few percent of the first, and is very small for the fuels of interest in this paper; it is related to the difference between the specific heats $C_{p}-C_{v}$, which is close to 0 ( $C_{p} / C_{v} \approx 1$ for liquids), so it will not be taken into account in this study ([3],[15],[19],[20]).

If the speed of sound $a$ could be determined as a function of $p$, at a constant temperature, and $\rho$ is measured at an initial point $\left(p_{o}=p_{\text {atm }}\right)$ Equation 7 could be satisfactory resolved for each isotherm, and density values could be obtained for high pressure values. Finally, knowing $a$ and $\rho$ values, then the bulk modulus could be obtained applying Equation 2. The technical characteristics of the experimental device used to obtain these properties values are explained in the next section.

\section{Experimental Setup}

The current work involves the measurement of two basic properties: speed of sound and density, allowing the further calculation of successive properties that are very difficult to obtain experimentally at high pressure conditions. The details of the systems used are described in this section. Three devices were used, the first one was the speed of sound test rig, and the others were the density instruments. All the variables measured and calculated are dependent on the fuel type, the pressure and temperature, so these parameters were precisely controlled and varied in order to have a wide range of results. 


\subsection{Speed of sound test rig}

As was mentioned before, one of the interests of the present study is to determine the speed of sound at typical diesel injection conditions, this means at a wide range of pressures and different temperatures. The speed of sound is obtained experimentally with great precision, based on the principle explained in the first part of Section 2, the pressure wave traveling ([18]). This is achieved by measuring the travel time of a pressure perturbation along a known distance.

In order to accomplish that aim, in particular the high pressure requirement, a special configuration was designed and coupled to the injection system. This technique has been used due to its simplicity and due to the fact that it is installed in series with the injection system. The schematic representation of the system is depicted in Figure 2. It can be seen that the common-rail injection system is used directly and a long high pressure pipe was located between the rail and the injector. Also, two pressure sensors were located in two different points of that long pipe, being able to measure any possible perturbation between both points. Specifically, the pressure waves were measured using high accuracy piezo-resistive Kistler Sensors, coupled to their respective amplifiers (pressure range 0-200 MPa). The length of the tube was long enough, permitting to place the pressure sensors far away, reaching an adequate time separation between the two signals, and a clear acquisition. Nevertheless, it was short enough, avoiding signal attenuation (length between sensors $=8.22 \mathrm{~m}$ ). The sample fuel was contained in that pipe, which had an inner diameter of $2.5 \mathrm{~mm}$. 
Inside the long pipe filled with the sample fuel, the pressure perturbation was produced by means of the injection event ([11]). The perturbations were depression waves generated as a consequence of the pressure drop produced in the tube when the injector was opened, owing to the fluid discharging toward the IDRCI ([21]). An example of the signals obtained is depicted in Figure 3.

The injection frequency was extremely small $(0.1 \mathrm{~Hz})$ with the purpose of avoiding wave interaction, and ensuring steady conditions inside the pipe. In addition, in order to avoid noises and compound waves that could be generated due to the interaction between forward and backward waves in the pipe, an additional high pressure line was coupled between the second pressure sensor and the rail ( 12m length), so the reflected waves are not present during the acquisition period.

The signals of the two pressure sensors were acquired by a data acquisition system (Yokogawa) and stored in a computer for further processing. Then, the travel time of a pressure perturbation could be determined systematically and its propagation speed could be computed using special algorithms (these algorithms calculated the initial point of the signal descending).

Speed of sound was measured for three fuels at all pressure and temperature values referred in Table 1.

In order to keep constant the temperature of the fuel in the high pressure system, a thermostatic bath filled with water was employed and regulated using an electronic controller. Moreover, the temperature was measured in five different points along the system: tank temperature, rail temperature, injector return temperature, IDRCI temperature and thermostatic bath temperature (this 
was the target temperature for the electronic controller), with a maximum variation of $1 \%$ during the experiments.

To have a good estimation of the experimental errors, several repetitive measurements were carried out at the same test points (line pressure and fuel temperature), and the obtained dispersion was about $\pm 0.5 \%$ with proper calibration of the equipment.

On the other hand, using this procedure for the speed of sound determination, the length of the pipe between the sensors $L$, must be accurately known as asserts Equation 1. Moreover, it is known that pipe length itself is affected by the pressure and temperature, then, it is crucial to introduce terms designed to correct it for these effects $([14],[22],[23])$. For this reason, the length variation $d L$ with temperature $T$ and pressure $p$ was calculated from Equation 8.

$$
d L=L_{o}\left[\alpha_{t}\left(T-T_{o}\right)+\beta_{t}\left(p-p_{o}\right)\right]
$$

where $\alpha_{t}$ and $\beta_{t}$ are the thermal coefficient and compressibility coefficient respectively of the stainless steel of the pipe. The original length difference $L_{o}$ was calibrated at a reference point $\left(T_{o}=298 \mathrm{~K}\right.$ and $\left.p_{o}=0.1 \mathrm{MPa}\right)$, by means of measurements with various alkanes as Decane and Dodecane and comparing with literature data ([24]), and detailed in Appendix A. Finally, the definitive distance between the sensors was $L=L_{o}+d L$.

\subsection{Density measurements}

Since the methodology used for density calculation is based on the integration of $(\partial \rho / \partial p)_{T}$, it is necessary to know the tendency of the density against the 
temperature at a reference pressure, in order to solve the equation. In this work the reference point chosen for the measurements was atmospheric pressure. Therefore, several density tests were performed at $p_{o}=0.1 \mathrm{MPa}$, using a conventional hydrometer, following the international standard method established in the ASTM-D1298. The hydrometers used were correctly calibrated (according to the international established rules), and the accuracy of the instrument could be estimated to be $\pm 5 \times 10^{-4} \mathrm{~kg} / \mathrm{m}^{3}$.

Moreover, a second instrument was used for corroborating the density values, given that they should be very accurate, since the further density values will depend on the reference points. The second instrument used was a Pycnometer (Afora, Spain), according to the procedure established in the ASTM-D1217, with a volume of $10 \mathrm{ml}$ and with a precision of $\pm 1.16 \times 10^{-4} \mathrm{ml}$ (properly calibrated at CMT - Motores Térmicos laboratories).

The measurements were carried out for several temperatures from $298 \mathrm{~K}$ up to $343 \mathrm{~K}$, increasing in steps of $10 \mathrm{~K}$. Likewise speed of sound measurements, the temperature was controlled using the mentioned thermostatic bath.

\subsection{Fuel Samples}

The fuels used for the experiments were very diverse, obtained from different processes, in agreement with the fuel variety available nowadays in the market and research area. These fuels were a biodiesel fuel: Rape Methyl Ester (typical bio-diesel used in Spain), a fuel used especially for winter season in cold countries (ARCT), and a conventional fossil diesel (Elite Fuel) delivered by Repsol and used as reference. These fuels have been chosen because it is 
very difficult to find wide information about biodiesels and other special fuels that can be used in diesel injection systems so far, especially when they are under high pressure condition. Details of these fuels can be seen in Table 2 .

\section{Results and Discussion}

In this section the experimental results are exposed, concerning density and speed of sound measurements. The properties values obtained for each fuel are listed and polynomial correlations are presented. With those values and following the methodology explained in previous sections the bulk modulus behavior as a function of pressure and temperature is shown.

\subsection{Speed of sound measurements}

As commented previously, the speed of sound determination consisted in measuring the time taken by an acoustic wave to travel along a known distance in the fluid samples, in this case it was the distance $L$ separating the two pressure transducers. As indicated in Table 1, measurements were carried out on ten isothermal, from $298 \mathrm{~K}$ until $343 \mathrm{~K}$ with a temperature increment of $5 \mathrm{~K}$, and for eight pressure levels, up to $180 \mathrm{MPa}$, and for each fuel. From the results, it was observed a variation of this property as a function of pressure and temperature. One example of this behavior is depicted in Figures 4 and 5, which present a group of the results obtained for the Reference fuel.

As expected, the value of speed of sound in the fuel increases with the pressure and decreases with temperature, coinciding with many previous studies ([14],[15],[25]). Temperature dependency is almost linear; in fact, when the 
statistical study is done, in the polynomial regression, the coefficient related to $T^{2}$ is not significant. On the other hand, the pressure dependency is different and is higher at lower temperatures.

In order to make this information easier to use, and for future calculations of densities and compressibility values, the data obtained for each isothermal curve were fitted to a polynomial expression (Equation 9).

$$
a=C_{1}+C_{2} p+C_{3} p^{2}+C_{4} p^{3}
$$

where $C_{1}, C_{2}, C_{3}$ and $C_{4}$ are the polynomial coefficients listed in Table 3 for each fuel studied. In this expression, the pressure is given in $\mathrm{MPa}$ and the speed of sound $a$ is in $\mathrm{m} / \mathrm{s}$.

The maximum deviation in the fitting expression is $\sim 1 \%$ for all the fuels, also the $R^{2}$ values are very close to the unit, hence the results and the empirical equation proposed could be considered accurate enough. The absolute values of speed of sound are different for all the sample fuels, but their trend against pressure and temperature are similar, as is shown in Figures 6 and 7. For the same pressure, the speed of sound is higher at lower temperatures, meaning that the speed of pressure waves will travel faster in the injection system at certain conditions, such as cold start situations. Besides, Figure 7 depicts that pressure waves are higher for RME fuel than for the reference fuel from atmospheric pressure up to $\sim 100 \mathrm{MPa}$ (depending on the pressure). At higher pressure, occurs the opposite behavior; this trend was also confirmed by other authors ([25]). These results provide useful information that should be taken into account in many injector modeling procedures (from the pump until the nozzle 
domain)([10],[26]), and also in many experimental techniques such as the injection rate measurement ([11]).

The results listed previously correspond to defined isothermal lines; however, in order to facilitate their application in future works, a generic expression of the speed of sound is presented as a function of both pressure and temperature. Hence, Equation 10 is obtained and its respective coefficients are shown in Table 4.

\subsection{Density Measurements}

Density measurements were made at ambient pressure $(0.1 \mathrm{MPa})$ and for several temperatures ( $298 \mathrm{~K}$ up to $343 \mathrm{~K}$, increasing each $10 \mathrm{~K}$ steps). For these measurements it was used the methodology explained in previous sections. For calibration, pure fuels were used as decane and dodecane, and the values obtained were compared with theoretical values provided by NIST ([24]), as it is described in Appendix A. After calibration, the initial densities of the three fluids at atmospheric pressure were measured. From those results it can be obtained a very simple empirical equation as a function of temperature for atmospheric pressure (Equation 11). In order to obtain $C_{5}$ and $C_{6}$ a linear regression was applied to experimental data, using an algorithm that iteratively reweighted least squares with a bisquare weighting function.

$$
\rho\left(p_{o}, T\right)=C_{5}+C_{6} T
$$

The polynomial coefficients are reported in Table 5, obtaining an overall uncertainty of $\sim 0.06 \%$. 


\subsection{Density at high pressure determination}

With the isothermal results of speed of sound at high pressures and density values at atmospheric pressure it is possible to calculate density at high pressures, taking into account the assumptions proposed in Section 2. Nevertheless, involving the isothermal condition implies that the temperature interval should be very small; otherwise calculations of the derivatives could introduce an additional uncertainty in the density calculated at high pressures. To avoid this inconvenient, Equation 11 is used, so the real experimental temperature of the speed of sound measurements is employed as the initial term $\rho\left(p_{o}, T\right)$ for density calculations at any pressure value.

Combining Equations 7 and 9, expression 12 is obtained:

$$
\rho(p, T)=\rho\left(p_{o}, T\right)+\int_{p_{0}}^{p} \frac{d p}{\left(C_{1}+C_{2} p+C_{3} p^{2}+C_{4} p^{3}\right)^{2}}
$$

Then $\rho$ values were obtained for a wide range of pressure for each isotherm. Figure 8 depicts de density values obtained from this procedure as a function of pressure, for all the sample fuels, at several isothermal lines. As expected, and in agreement with previous studies, the density increases with pressure and decreases with temperature.

Figure 9 compares two different isotherms for all the fuels studied, at $298 \mathrm{~K}$ and $343 \mathrm{~K}$. For all the pressures the reference fuel had approximately $5 \%$ lower density than the biofuel tested, and approximately $1.5 \%$ higher than winter fuel. This is an important difference that should be taken into account for the substitution of reference fuel with biodiesel. Therefore, the total fuel mass will increase for the same volume injected during the injection event inside the 
combustion chamber when biodiesel is used. Nevertheless, regardless of Biodiesel will increase the fuel mass, the engine power could be diminished due to the lower heat capacity of biofuels [27]. These effects would be minor when winter fuel is used because the density difference is small.

On the other hand, Figure 10 depicts density values for two isobaric lines $(0.1$ $\mathrm{Mpa}$ and $180 \mathrm{MPa}$ ). It can be seen that the density drop is more notorious for pressure ranges than for temperature (considering diesel engine limits). This information should be taken into account in the study of some elements of the engine as nozzle injector, where the pressure drop is very high and so far the density value has been considered constant, despite the fact that maybe it is variable as shown the results presented in the current work.

From the experimental and calculated values, a generic equation can be derived as a function of pressure and temperatures, in order to facilitate the information usage. The polynomial structure chosen for the correlations is a common polynomial function used in many thermal libraries and softwares dedicated to the hydraulic modeling; then, the empirical information could be coupled to those useful modeling tools. The equation and the respective coefficients are listed in Table 6.

\subsection{Bulk Modulus Determination}

Finally, with the experimental values of speed of sound and calculated density values, the bulk modulus is obtained applying Equation 2 for the wide range of pressures and temperatures. 
The obtained results are represented along a few isotherms in Figure 11 for the reference fuel. It is observed from this figure that the dependency of the bulk modulus with respect to pressure is almost linear and increases with pressure. Some authors have stated that the lower bulk modulus of fluids at lower pressures is because of the existence of free space between the loosely packed molecules. When the pressure increases the bulk modulus also increases due to the own compression of the tightly molecules, creating a resistance generated by the intermolecular repulsion, then opposing to further compression increments ([15], [28]).

Figure 12 illustrates the bulk modulus for two isothermal lines, for all the sample fuels studied. The higher values correspond to biodiesel fuel. The different bulk modulus observed could affect the behavior of the flow in diesel injection systems, especially the in-line pump-line-nozzles, in which the injection timing depends strongly on wave travelling. Furthermore, this could also affect the pollutant emissions of engines when in-line rotary pumps are used ([12]). Besides, the bulk modulus of winter fuel is very similar to reference fuel, and is almost the same at higher pressures where they are overlapped.

The trend observed for the isobaric lines, when the bulk modulus decrease with temperature, in analogy with the density and speed of sound trend, is depicted Figure 13. Finally, the data obtained were fitted to the polynomial expression Equation 14, where both pressure and temperature are fitted to linear coefficients, according to the trend observed in bulk modulus Figures. The coefficients are listed in Table 7. 


\section{Conclusions}

This study was done in order to evaluate the effects of temperature and high pressures on three thermophysical properties of some fuels. So far, the information available regarding the thermophysical properties of fuels at high pressure (up to $180 \mathrm{MPa}$ ), was almost inexistent. Three fuel samples were studied, winter fuel, Rape Methyl Ester and a reference fuel.

Values of speed of sound were obtained experimentally using a modified injection system test rig. In general, it was observed an increase with pressure and a decrease with temperature. For low pressures the biofuel had the higher speed of sound, and could affect the dynamic of some injection elements (for pump-line-injector type systems), advancing or delaying the injection event, and therefore the combustion performance.

Density values at atmospheric pressure were measured. Using these values together with experimental data of speed of sound, it was computed the density values of the fuels at high pressure following the detailed methodology. As expected, density values increased with pressure and decreased with temperature. Also, biodiesel fuel density is $\sim 5 \%$ higher than reference fuel density, increasing the injected quantity in the combustion chamber (for the same volume). Besides, winter fuel density is $\sim 1.5 \%$ lower than reference fuel density, so the difference could be neglected.

For all the fuels the bulk modulus increased linearly with pressure, and for the pressure range studied the bulk modulus of biodiesel was $\sim 7 \%$ higher than diesel fuel. In addition, the bulk modulus of Arctic fuel was very similar, $~ 3 \%$ 
lower than diesel fuel for low pressure, and almost the same for high pressure values. Also, as was expected, the bulk modulus increased with density. These data, owing to the variety of the properties studied and the extend of the pressure and temperature domain covered, will be useful for further applications and research in engine development, like high injection pressure system modeling, combustion computations, etc.

\section{Acknowledgements}

This research has been funded in the frame of the Project "Caracterización experimental de la cavitación en el flujo interno e influencia sobre modelos de chorro Diesel", Reference TRA2007-68006-C02-01, from MINISTERIO DE CIENCIA E INNOVACIÓN from Spain.

\section{References}

[1] Park SH, Kim HJ, Suh HK, Lee CS. Experimental and numerical analysis of spray-atomization characteristics of biodiesel fuel in various fuel and ambient temperatures conditions. International Journal of heat and fluid flow $2009 ; 30: 960-70$.

[2] Tat ME, Van Gerpen JJ, Soylu S, Canakci M, Monyem A, Wormley S. The Speed of Sound and Isentropic Bulk Modulus of biodiesel at 21 degrees from atmospheric pressure to 35MPa. J. Am. Oil Chem. Soc. 2000; 77: 285-89.

[3] Boehman AL, Morris D, Szybist J. The impact of bulk Modulus of Diesel fuels on fuel injection timing. Energy \& Fuels 2004; 18:1877-82. 
[4] Benajes J, Pastor JV, Payri R, Plazas AH. Analysis of the Influence of diesel nozzle geometry in the injection rate characteristic. Journal of the Fluids Engineering 2004; 126:63-71.

[5] Rodriguez-Anton LM, Casanova-Kindelan J, Tardajos G. High pressure physical properties of fluids used in diesel injection Systems. SAE paper 2000-01-2046; 2000.

[6] Payri R, García JM, Salvador FJ, Gimeno J. Using spray momentum flux measurements to understand the influence of diesel nozzle geometry on spray characteristics. Fuel 2005; 84:551-61.

[7] Siebers D. Liquid-phase fuel penetration in diesel sprays. SAE paper $980809 ; 1998$.

[8] Lujan JM, Tormos B, Salvador FJ, Gargar K. Comparative analysis of a DI diesel engine fuelled with biodiesel blends during the European MVEG-A cycle: Preliminary study (I).Biomass and Bioenergy 2009; 33:941-47.

[9] Boudy F, Seers P. Impact of physical properties of biodiesel on the injection process in a common-rail direct injection system. Energy Conversion and Management 2009; 50:2905-12.

[10] Payri R, Tormos B, Salvador FJ, Plazas AH. Using one-dimensional modeling codes to analyze the influence of diesel nozzle geometry on injection rate characteristics. Int. J. Vehicle Design 2005; 38:58-78.

[11] Payri F, Salvador FJ, Gimeno J, Bracho G. A new methodology for correcting the signal cumulative phenomenon on injection rate measurements. Experimental Techniques 2008; 32:46-49.

[12] Kegl B. Biodiesel usage at low temperature. Fuel 2008; 87:1306-17. 
[13] Payri R, Salvador FJ, Gimeno J, Bracho G. Effect of fuel properties on diesel spray development at extreme cold conditions. Proceedings of the institution of mechanical engineers part D-Journal of automobile engineering $2008 ; 222: 1743-53$.

[14] Dávila MJ, Trusler JPM. Thermodynamic properties of mixtures of Nmethyl-2-pyrrolidinone and methanol at temperatures between $298,15 \mathrm{~K}$ and 343.15K and pressures up to $60 \mathrm{MPa}$. J. Chem. Thermodynamics 2009; 41:35 -45 .

[15] Daridon JL, Lagrabette A, Lagourette B. Speed of sound, density, and compressibilities of heavy synthetic cuts from ultrasonic measurements under pressure. J. Chem. Thermodynamics 1998;30:607-23.

[16] Trusler JPM. Physical Acoustics and Metrology of Fluids. New York: Taylor and Francis Group; 1991.

[17] Douheret G, Davis MI, Rais JCR, Blandamer MJ. Isentropic compressibilities - experimental origin and the quest for their rigorous estimation in thermodynamically ideal liquid mixtures. Chem. Phys. Chem. 2001;2:148-61.

[18] Winterbone DE, Pearson RJ. Theory of Engine Manifold Design. Wave Action Methods for IC Engines. London: Professional Engineering Publishing; 2000.

[19] Hayward AT. How to measure the isothermal compressibility of liquids accurately. J. Physics. D: Appl. Phys. 1971;4: 938-50.

[20] Esperança JMSS, Visak ZP, Plechkova NV, Seddon KR, Guedes HJR, Rebelo LPN. Density, speed of sound and derived thermodynamic properties 
of ionic liquids over an extended pressure range. J.Chem. Eng. Data 2006;51: 2009-15.

[21] Bianchi GM, Falfari S, Parotto M, Osbat G. Advanced modeling of common rail injector dynamics and comparison with experiments. SAE Paper 2003-010006; 2003.

[22] Plantier F, Daridon JL, Lagourette B. Measurement of the B/A nonlinearity parameter under high pressure: Application to water. J. Acoust. Soc. Am. 2002; 111:707-15.

[23] Ball SJ, Trusler JPM. The speed of Sound and derived thermodynamic properties of $\mathrm{n}$-Hexane and $\mathrm{n}$-hexadecane at temperatures between $298 \mathrm{~K}$ and $373 \mathrm{~K}$ and pressures up to $100 \mathrm{MPa}$. International Journal of Thermophysics $2001 ; 22: 427-43$.

[24] http://webbook.nist.gov/chemistry/fluid/.

[25] Rodriguez - Anton LM, Aparicio C, Guignon B, Sanz PD. Volumetric properties at high pressure of waste oil methyl ester compared with diesel oil. Fuel 2008;87:1934-40.

[26] Salvador FJ, Romero JV, Roselló MD, Martínez-López J. Validation of a code to model cavitation phenomena in diesel injector nozzles. Mathematical and Computer Modelling. Doi:10.1016/j.mcm.2010.02.027.

[27] Armas O, Yehliu K, Boehman AL. Effect of alternative fuels on exhaust emissions during diesel engine operation with matched combustion phasing. Fuel 2010;89:438-56.

[28] Bridgman PW. The Physics of High Pressure. London: G. Bell and Sons; 1958, p. $116-49$. 


\section{APENDIX A.}

The measurement devices were calibrated using pure fuels as alkanes, specifically decane and dodecane. The theoretical values were obtained from NIST laboratories [24].

For the speed of sound measurements, the experimental measurements were done up to $80 \mathrm{MPa}$ because of two reasons: the theoretical values available are up to $75 \mathrm{MPa}$, and for safety operation of the pump (the viscosity of such liquids is very low, so the pump was not lubricated enough). The temperature was properly controlled and maintained at $303 \mathrm{~K}$. In order to obtain the experimental values, the methodology explained in section 2 was applied. Moreover, it was possible to calibrate the original length difference $L_{o}$, crucial for the calculations. For the tested points, it can be seen that the experimental values reproduced very well the theoretical values, depicted in Figure A.1. Then, the method could be considered accurate.

Additionally, the density instruments were also calibrated using these pure fuels. The tests were done at atmospheric pressure and for a wide range of temperatures. The density behavior is depicted in Figure A.2, and it can be seen that there is good agreement between the experiments and the theory, so the method is reliable. 


\section{LIST OF TABLES}

Table 1. Fuel test conditions.

Table 2. Fuel general properties.

Table 3: Polynomial coefficients for Eq. 9 and R2 values.

Table 4. Polynomial coefficients for speed of sound (Eq. 10) and R2 values.

Table 5. Polynomial coefficients for density (Eq. 11) and R2 values at atmospheric pressure.

Table 6. Polynomial coefficients for Density (Eq. 13) and R2 values.

Table 7. Polynomial coefficients for Bulk Modulus (Eq. 14) and R2 values. 


\section{LIST OF FIGURES}

Figure 1. Propagation of a linear wave.

Figure 2. Scheme of the speed of sound Test Rig.

Figure 3. Example of pressure waves acquired with pressure sensors.

Figure 4. Speed of sound results for Reference fuel. Isothermal curves: $+T$ $298 \mathrm{~K}, * \mathrm{~T} 308 \mathrm{~K}, \times \mathrm{T} 318 \mathrm{~K}, \bullet \mathrm{T} 328 \mathrm{~K}, \boldsymbol{\nabla} \mathrm{T} 338 \mathrm{~K}, \bullet \mathrm{T} 348 \mathrm{~K}$.

Figure 5. Speed of sound results for Reference fuel. Isobaric curves: $+p$

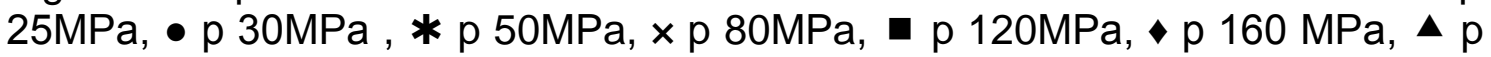
180MPa.

Figure 6. Speed of sound values obtained from Eq. 9 as function of temperature, at two isobaric curves. Continuous line $0.1 \mathrm{MPa}$, dashed line $25 \mathrm{MPa}$. O Reference Fuel, *Arctic Fuel, $\boldsymbol{\nabla}$ RME Fuel.

Figure 7. Speed of sound values obtained from Eq. 9 as function of pressure, at two isothermal curves. Continuous line 298K, dashed line 343K. O Reference Fuel, *Arctic Fuel, $\boldsymbol{\nabla}$ RME Fuel.

Figure 8. Density results for Reference fuel (Eq. 12). Isothermal curves: $+T$ $298 \mathrm{~K}, * \mathrm{~T} 308 \mathrm{~K}, \times \mathrm{T} 318 \mathrm{~K}, \bullet \mathrm{T} 328 \mathrm{~K}, \boldsymbol{\nabla} \mathrm{T} 338 \mathrm{~K}, \bullet \mathrm{T} 348 \mathrm{~K}$.

Figure 9. Density values obtained from Eq. 12. Isothermal curves: OReference Fuel, * Arctic Fuel, $\nabla$ RME Fuel. Continuous Line: T298K. Dashed line: T343K.

Figure 10. Density values obtained from Eq. 12. Isobaric curves: O Reference Fuel, * Arctic Fuel, $\boldsymbol{\nabla}$ RME Fuel. Continuous Line: P 0.1MPa. Dashed line: P180MPa.

Figure 11. Bulk Modulus results for Reference fuel. Isothermal curves: $+T$ $298 \mathrm{~K}, * \mathrm{~T} 308 \mathrm{~K}, \times \mathrm{T} 318 \mathrm{~K}, \bullet \mathrm{T} 328 \mathrm{~K}, \boldsymbol{\nabla} \mathrm{T} 338 \mathrm{~K}, \bullet \mathrm{T} 348 \mathrm{~K}$.

Figure 12. Bulk Modulus values obtained. Isothermal curves. O Reference Fuel, *Arctic Fuel, $\boldsymbol{\nabla}$ RME Fuel. Continuous line: T298K. Dashed Line: T343K.

Figure 13. Bulk Modulus values. Isobaric curves. O Reference Fuel, *Arctic Fuel, $\boldsymbol{\nabla}$ RME Fuel. Continuous Line: P 0.1MPa. Dashed line: P180MPa.

Figure A.1. Speed of Sound values for Decane and Dodecane at $T=303 \mathrm{~K}$

Figure A.2. Density values used for system calibration. 
Table 1. Fuel test conditions

\begin{tabular}{ccc}
\hline Fuels & $\begin{array}{c}\text { Temperature } \\
\text { (K) }\end{array}$ & $\begin{array}{c}\text { Pressure } \\
\text { (MPa) }\end{array}$ \\
\hline Reference Fuel & 298 & \\
(Ref) & 303 & 15 \\
& 308 & 25 \\
Rape Methyl Ester & 313 & 30 \\
(RME) & 318 & 50 \\
& 323 & 80 \\
& 328 & 120 \\
Winter Fuel & 333 & 160 \\
(Arct) & 338 & 180 \\
& 343 & \\
\hline
\end{tabular}


Table 2. Fuel general properties

\begin{tabular}{cccc}
\hline Fuels & $\begin{array}{c}\text { Density } \\
{\left[\mathrm{Kg} / \mathbf{m}^{3}\right]}\end{array}$ & $\begin{array}{c}\text { Viscosity } \\
{\left[\mathrm{mm}^{2} \mathbf{s}^{-1}\right]}\end{array}$ & $\begin{array}{c}\text { Surface Tension } \\
{[\mathrm{N} / \mathrm{m}]}\end{array}$ \\
\hline Reference Fuel & 825 & 2.34 & 0.0205 \\
Rape Methyl Ester & 863 & 4.47 & 0.028 \\
Winter Fuel & 812 & 2.06 & 0.022 \\
\hline
\end{tabular}


Table 3: Polynomial coefficients for Eq. 9 and $R^{2}$ values

\begin{tabular}{|c|c|c|c|c|c|}
\hline Temp [K] & $C_{1}$ & $C_{2}$ & $C_{3}$ & $C_{4}$ & $\mathbf{R}^{2}$ \\
\hline \multicolumn{6}{|c|}{ Reference Fuel } \\
\hline 298 & 1338.72 & 5.38 & -0.02136 & 4.78E-05 & 0.994 \\
\hline 303 & 1317.45 & 5.78 & -0.02973 & 8.42E-05 & 0.996 \\
\hline 308 & 1312.30 & 4.19 & -0.00552 & $-2.92 \mathrm{E}-06$ & 0.999 \\
\hline 313 & 1305.25 & 4.54 & -0.00612 & $-1.15 E-05$ & 0.993 \\
\hline 318 & 1301.25 & 4.40 & -0.00663 & $-2.42 \mathrm{E}-06$ & 0.999 \\
\hline 323 & 1258.86 & 5.55 & -0.02194 & 5.55E-05 & 0.997 \\
\hline 328 & 1245.49 & 5.52 & -0.01710 & 2.61E-05 & 0.996 \\
\hline 333 & 1237.33 & 5.64 & -0.02363 & 5.95E-05 & 1.000 \\
\hline 338 & 1203.16 & 6.20 & -0.02586 & 6.02E-05 & 1.000 \\
\hline 343 & 1188.40 & 4.59 & -0.00544 & $-8.42 \mathrm{E}-06$ & 0.999 \\
\hline \multicolumn{6}{|c|}{ Rape Methyl Ester } \\
\hline 298 & 1377.57 & 3.74 & -0.00174 & $-2.50 \mathrm{E}-05$ & 0.992 \\
\hline 303 & 1363.70 & 3.89 & -0.00906 & $1.50 \mathrm{E}-05$ & 0.994 \\
\hline 308 & 1314.62 & 5.99 & -0.03118 & 8.07E-05 & 0.991 \\
\hline 313 & 1310.88 & 5.15 & -0.02002 & 4.64E-05 & 0.993 \\
\hline 318 & 1291.93 & 5.35 & -0.02030 & 4.48E-05 & 0.995 \\
\hline 323 & 1285.91 & 4.98 & -0.01415 & 1.97E-05 & 0.996 \\
\hline 328 & 1275.30 & 2.95 & 0.01052 & $-6.04 E-05$ & 0.993 \\
\hline 333 & 1244.02 & 5.99 & -0.02932 & 8.08E-05 & 0.997 \\
\hline 338 & 1226.27 & 6.21 & -0.03093 & 8.36E-05 & 0.999 \\
\hline 343 & 1213.00 & 5.04 & -0.01532 & 3.05E-05 & 0.998 \\
\hline \multicolumn{6}{|c|}{ Winter Fuel } \\
\hline 298 & 1355.32 & 4.54 & -0.00864 & $-2.85 E-06$ & 0.998 \\
\hline 303 & 1330.40 & 4.66 & -0.01014 & 1.05E-05 & 0.997 \\
\hline 308 & 1317.10 & 5.58 & -0.02112 & 4.81E-05 & 0.999 \\
\hline 313 & 1311.54 & 3.91 & -0.00067 & $-2.00 \mathrm{E}-05$ & 0.999 \\
\hline 318 & 1298.45 & 3.96 & 0.00016 & $-2.17 \mathrm{E}-05$ & 0.998 \\
\hline 323 & 1295.16 & 3.61 & 0.00572 & $-4.51 \mathrm{E}-05$ & 0.998 \\
\hline 328 & 1264.71 & 4.17 & -0.00068 & $-2.27 E-05$ & 0.999 \\
\hline 333 & 1238.40 & 6.27 & -0.02667 & 6.83E-05 & 0.999 \\
\hline 338 & 1223.49 & 4.84 & -0.00826 & 8.34E-07 & 0.998 \\
\hline 343 & 1186.07 & 6.01 & -0.02358 & 5.93E-05 & 0.999 \\
\hline
\end{tabular}


Table 4. Polynomial coefficients for speed of sound (Eq. 10) and $R^{2}$ values

\begin{tabular}{ccccccc}
\hline \multicolumn{5}{c}{$a=k 1+k 2\left(T-T_{o}\right)+k 3\left(p-p_{o}\right)+k 4\left(p-p_{o}\right)^{2}+k 5\left(p-p_{o}\right)\left(T-T_{o}\right)$} & $(10)$ \\
\hline Fuel & $\boldsymbol{k} \mathbf{1}$ & $\boldsymbol{k 2}$ & $\boldsymbol{k 3}$ & $\boldsymbol{k 4}$ & $\boldsymbol{k 5}$ & $\mathbf{R 2}$ \\
\hline REF & 1363.05 & -3.11349 & 4.1751 & -0.00696763 & 0.00940137 & 0.9959 \\
Arct & 1355.84 & -3.32715 & 4.3013 & -0.00714654 & 0.0119425 & 0.9969 \\
RME & 1385.7 & -3.06884 & 3.83734 & -0.00650776 & 0.0116338 & 0.9933 \\
\hline
\end{tabular}


Table 5. Polynomial coefficients for density (Eq. 11) and $R^{2}$ values at atmospheric pressure

\begin{tabular}{cccc}
\hline & RME & Ref & Arct \\
\hline$C_{5}$ & 1079.9388 & 1026.0362 & 1018.6467 \\
$C_{6}$ & -0.6928 & -0.6416 & -0.6600 \\
$\mathrm{R}^{2}$ & 0.9952 & 0.9979 & 0.9967 \\
\hline
\end{tabular}


Table 6. Polynomial coefficients for Density (Eq. 13) and $R^{2}$ values

\begin{tabular}{cccccccc}
\hline \multicolumn{6}{c}{$\rho=k 1+k 2\left(T-T_{o}\right)+k 3\left(p-p_{o}\right)+k 4\left(p-p_{o}\right)^{2}+k 5\left(T-T_{o}\right)^{2}+k 6\left(p-p_{o}\right)\left(T-T_{o}\right)$} & $(13)$ \\
\hline Fuel & $\boldsymbol{k} \mathbf{1}$ & $\boldsymbol{k 2}$ & $\boldsymbol{k 3}$ & $\boldsymbol{k 4}$ & $\boldsymbol{k} 5$ & $\boldsymbol{k 6}$ & $\mathbf{R 2}$ \\
\hline REF & 835.698 & -0.6280 & 0.4914 & -0.00070499 & 0.00073739 & 0.00103633 & 0.9998 \\
Arct & 821.468 & -0.5615 & 0.4951 & -0.00072810 & 0.00018393 & 0.00103526 & 0.9998 \\
RME & 874.584 & -0.6991 & 0.4790 & -0.00063634 & 0.0009704 & 0.00091866 & 0.9999 \\
\hline
\end{tabular}


Table 7. Polynomial coefficients for Bulk Modulus (Eq. 14) and $R^{2}$ values

\begin{tabular}{|c|c|c|c|c|}
\hline \multicolumn{5}{|c|}{$B=k 1+k 2\left(T-T_{o}\right)+k 3\left(p-p_{o}\right)$} \\
\hline Fuel & $k 1$ & $k 2$ & $k 3$ & $\mathbf{R}^{2}$ \\
\hline REF & 1581.27 & -7.2870 & 9.4233 & 0.9947 \\
\hline Arct & 1522.92 & -6.9863 & 9.7161 & 0.9947 \\
\hline RME & 1697.52 & -7.0479 & 9.1896 & 0.9909 \\
\hline
\end{tabular}




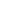

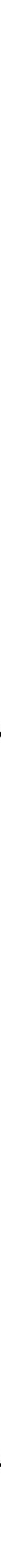




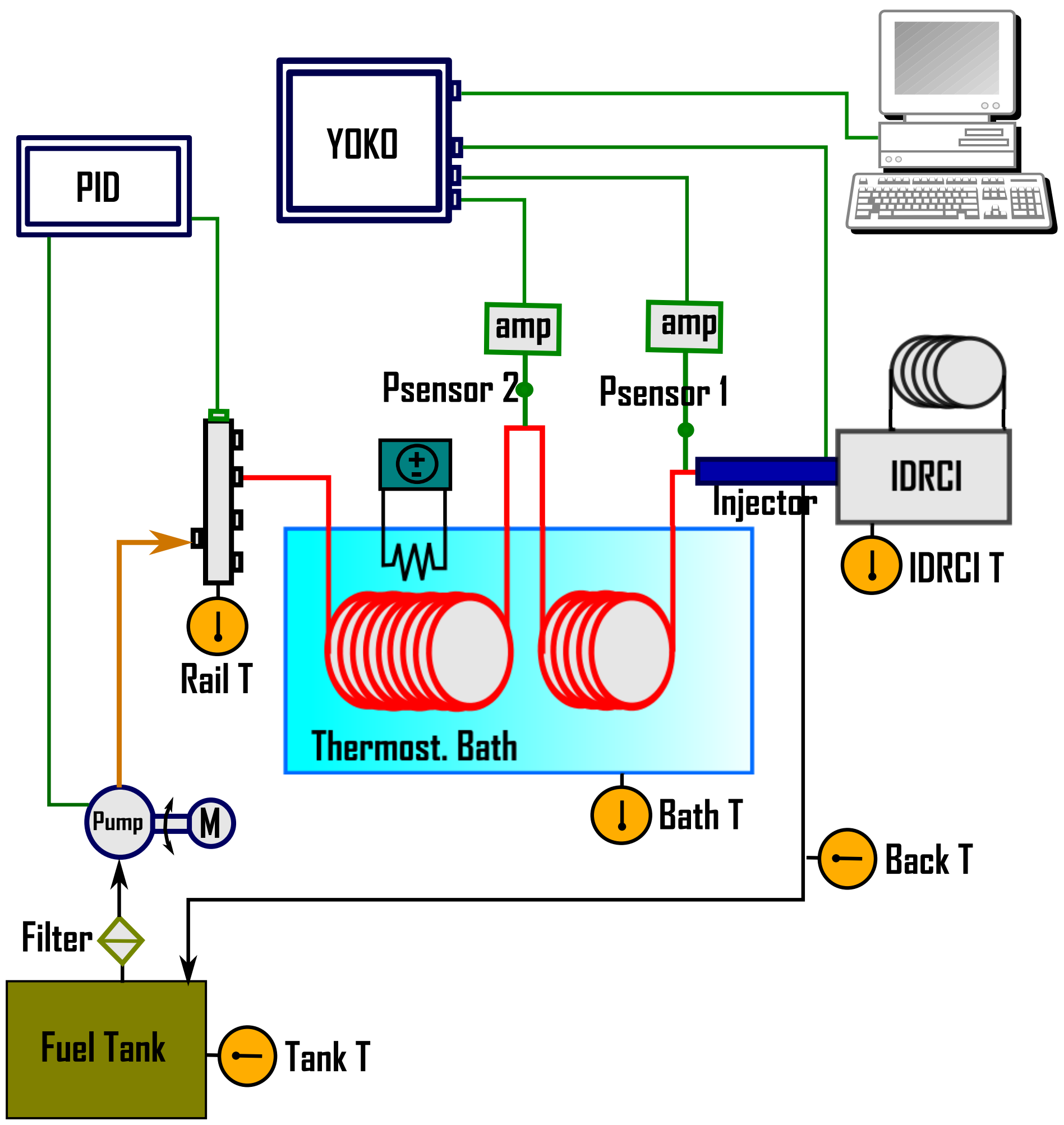

\section{System components:}

- $\quad$ Fuel Tank

- Injection Kit: injection pump, electrical engine, high pressure lines, common-rail, control system.

- $\quad$ High pressure line, (2.5mm inner diameter)

- $\quad$ Thermostatic Bath: refrigerated with water.

- 2 pressure sensors (Psensor)

- $\quad$ Siemens Piezoelectric Injector, used to generate the pressure wave

- $\quad$ Injected mass was discharged into the IDRCI

- Data acquisition system: YOKOGAWA DL708E 


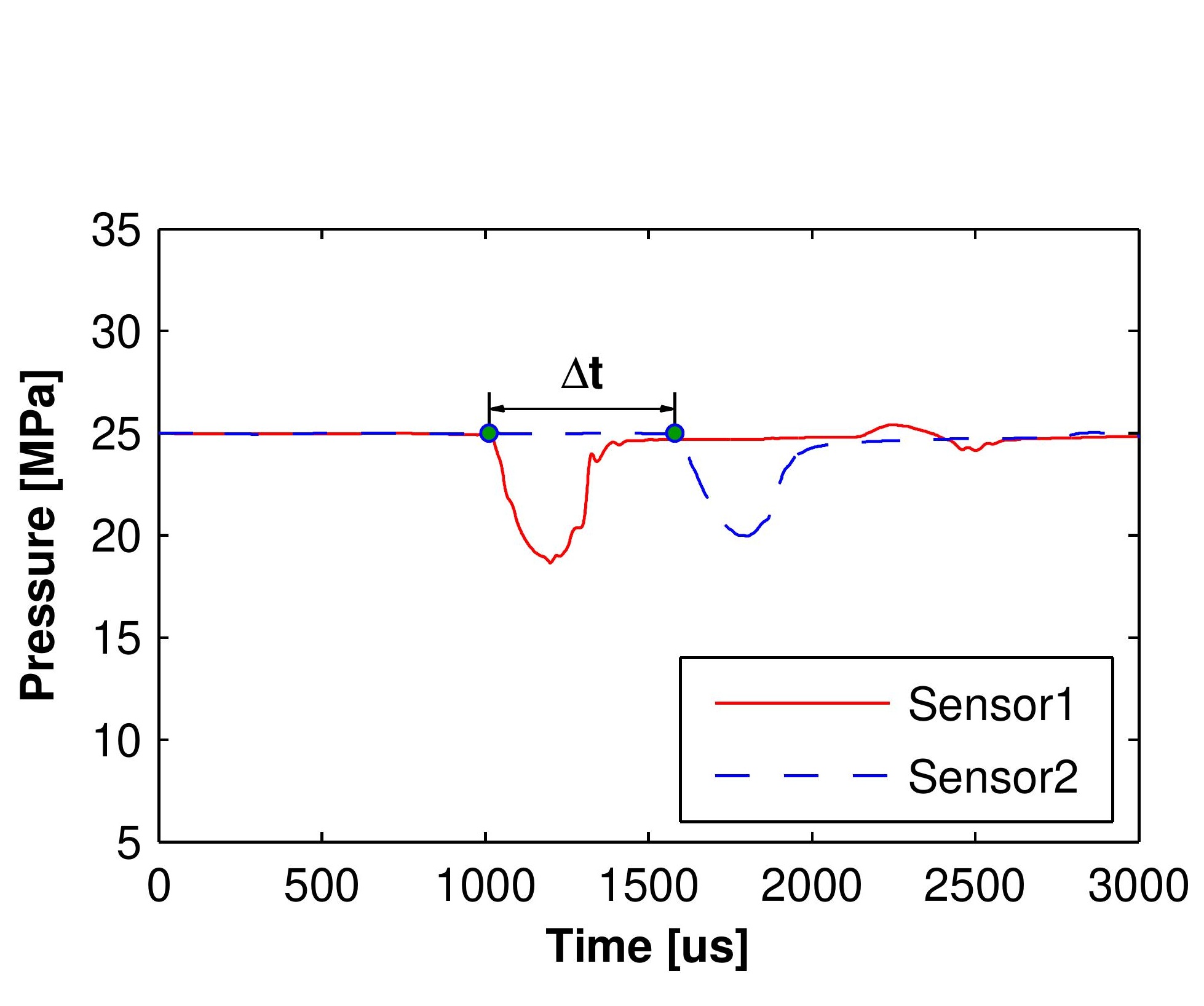

Figure 3

3

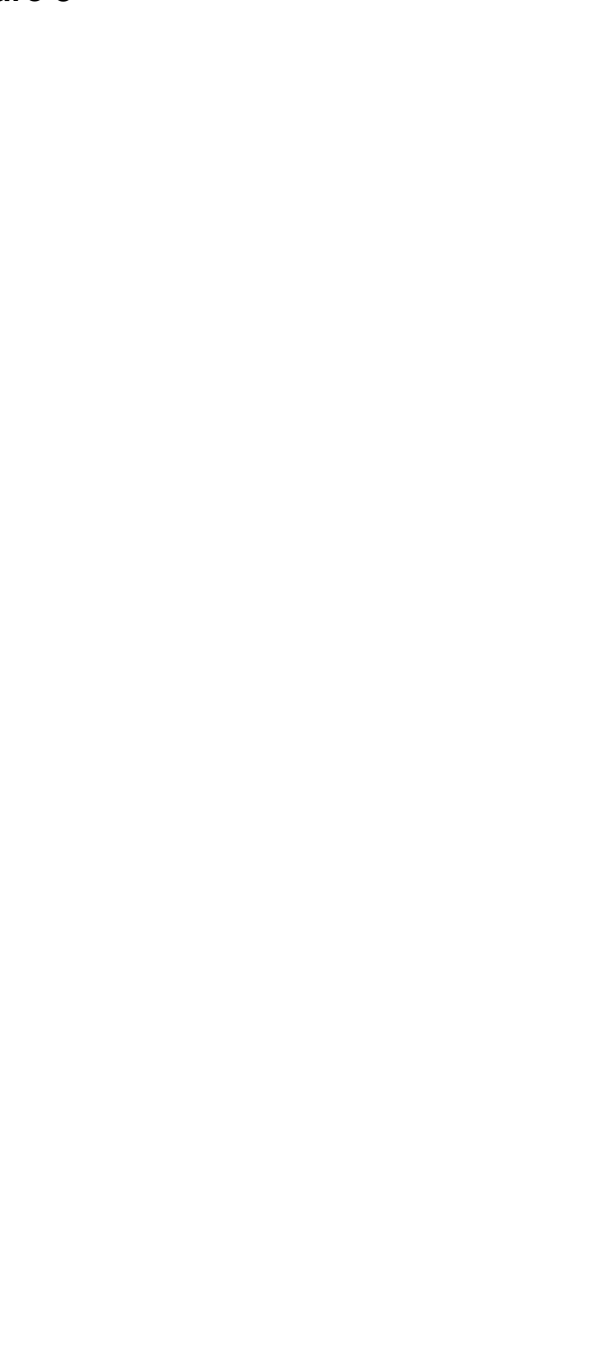

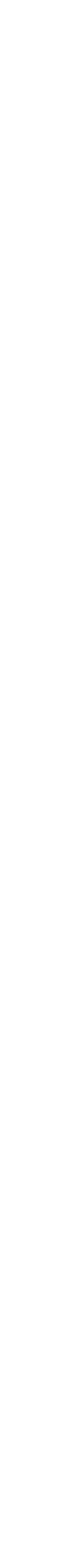

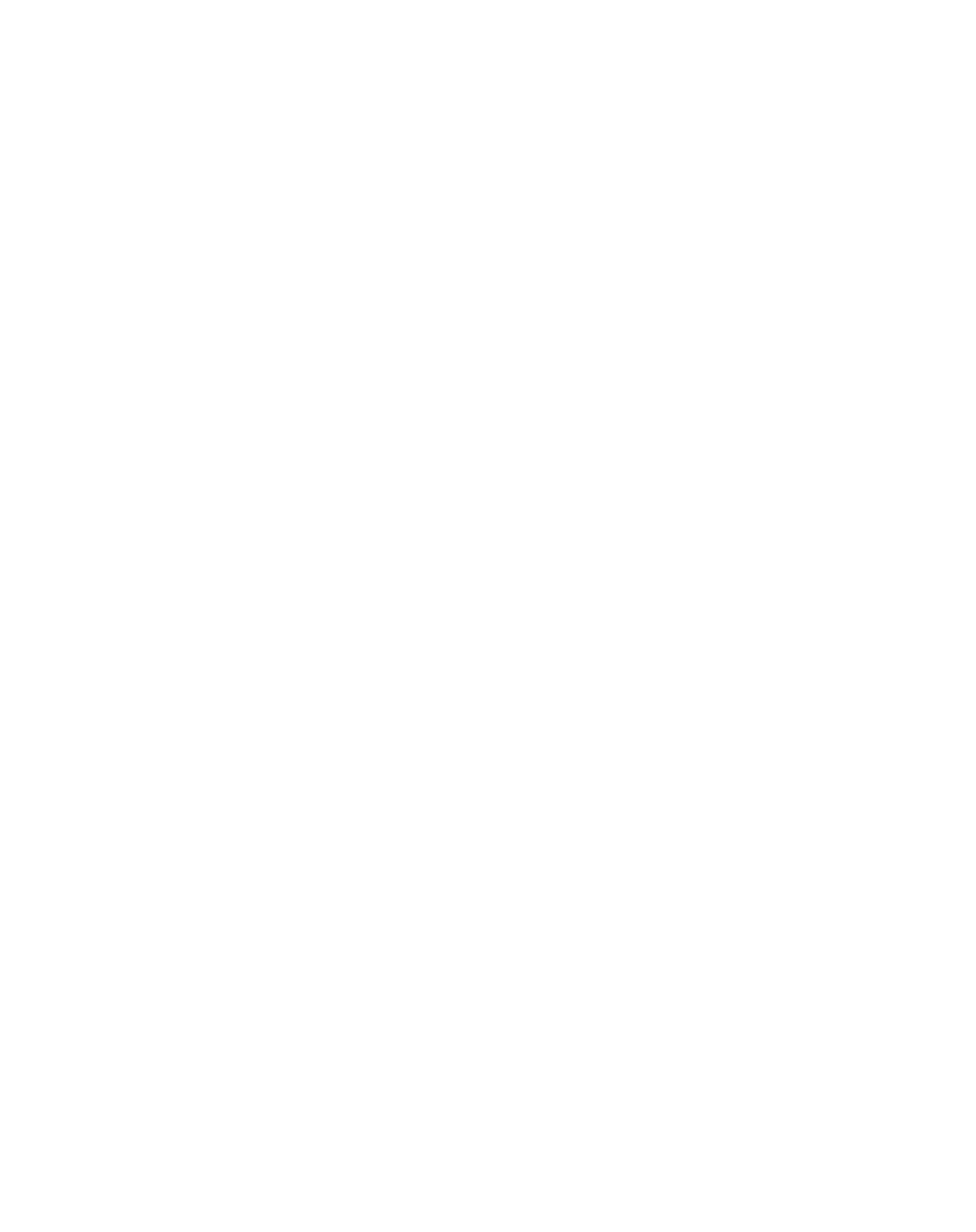


Figure 10

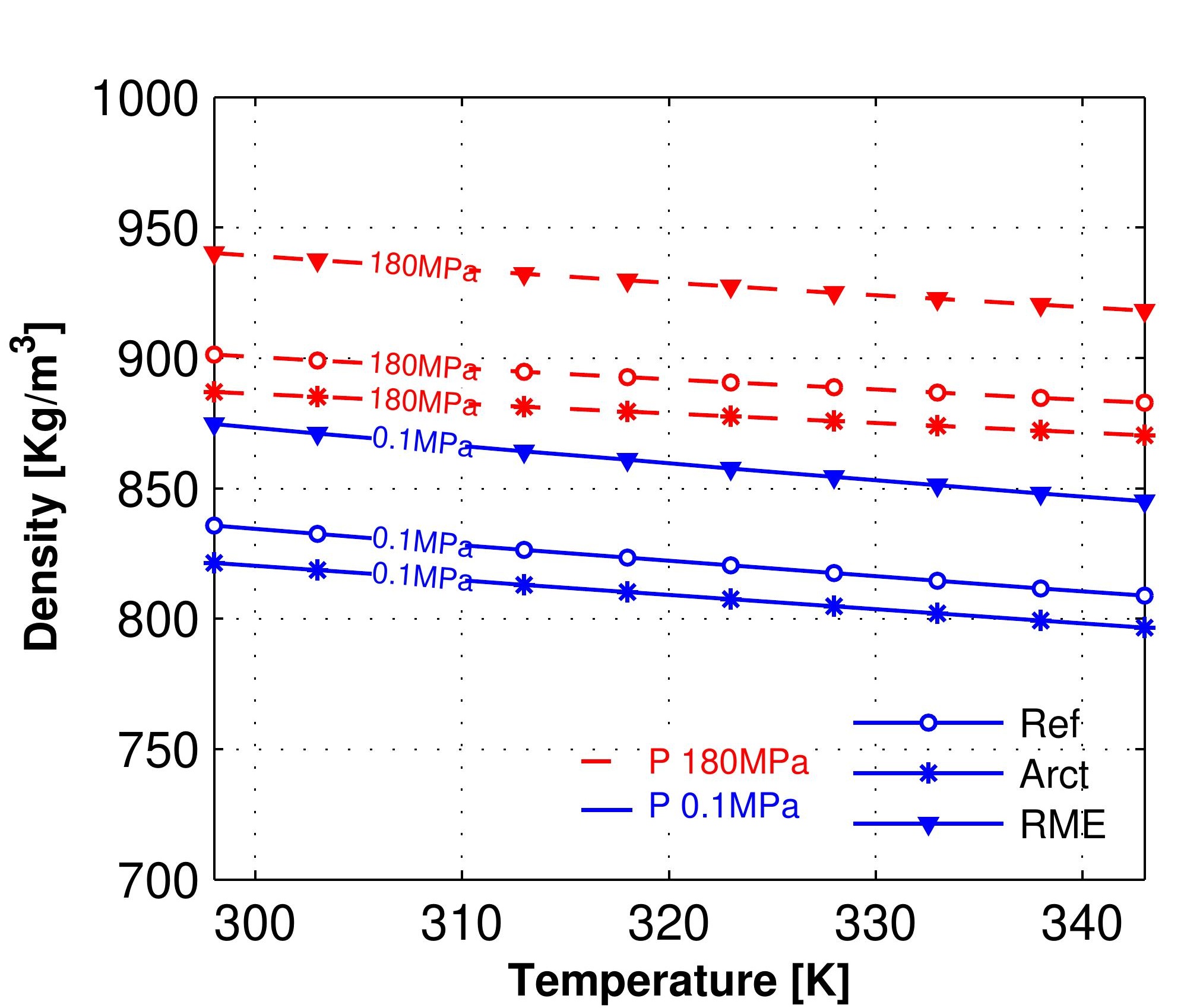

Figure 10

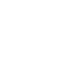
-
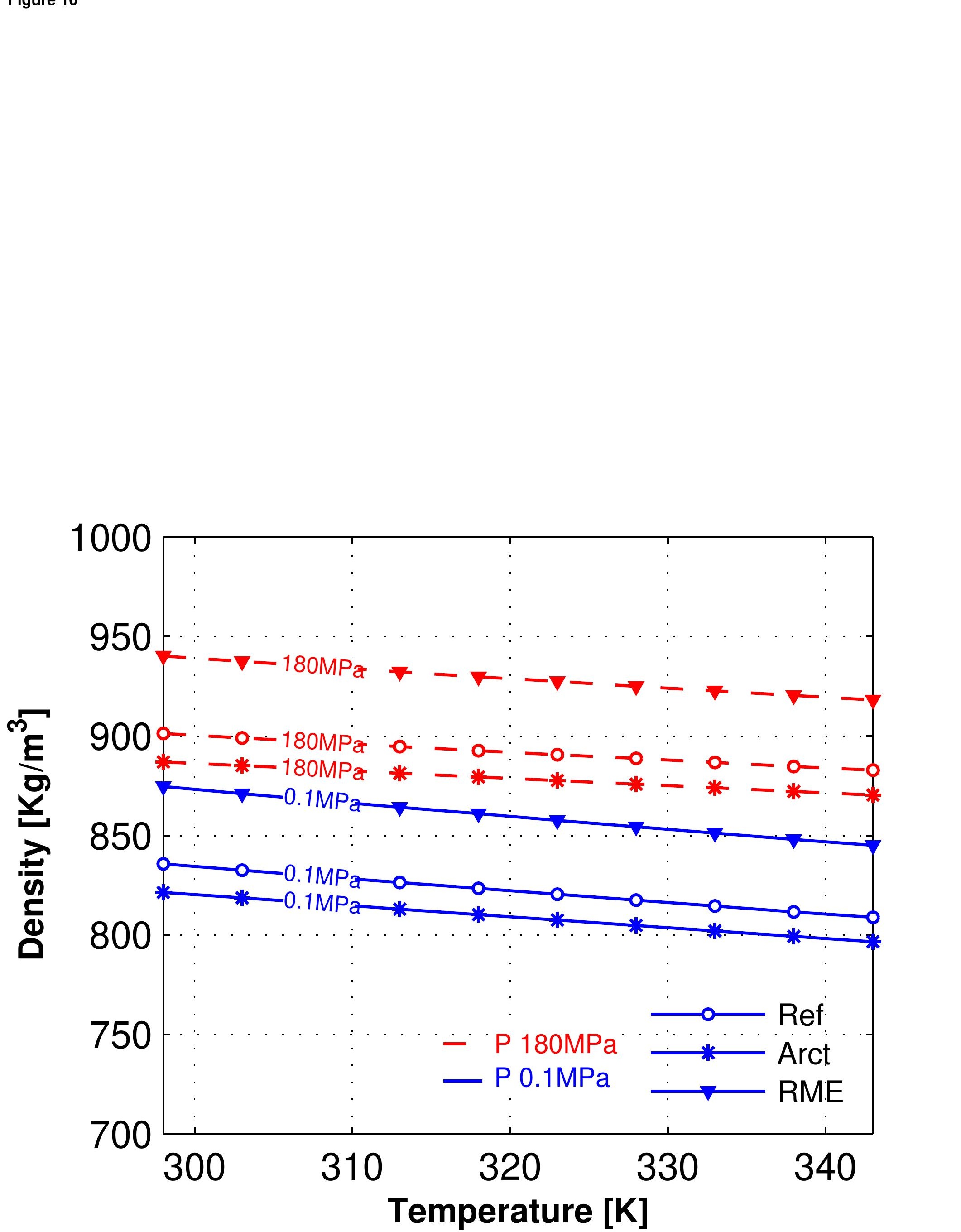


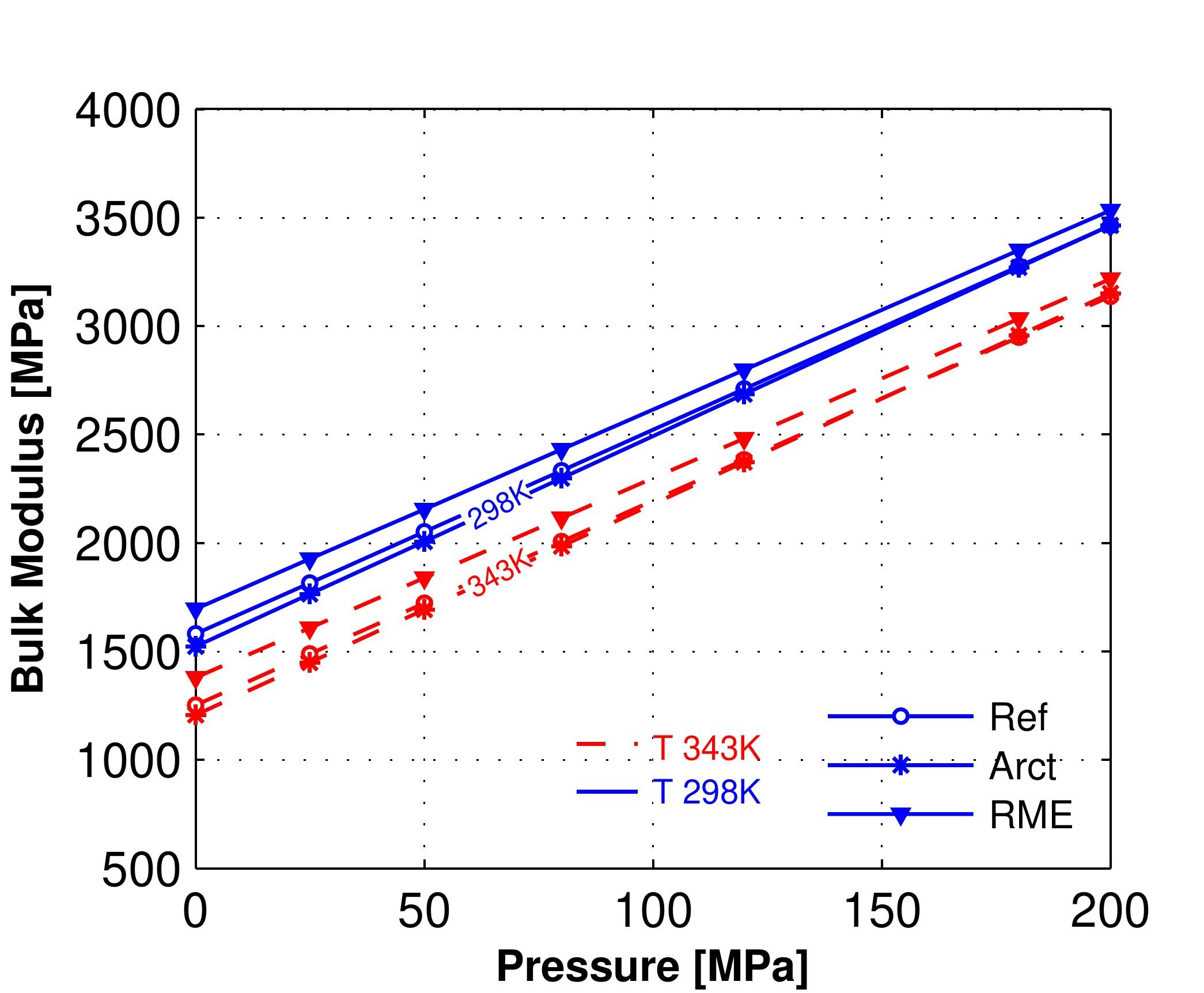

Figure 12
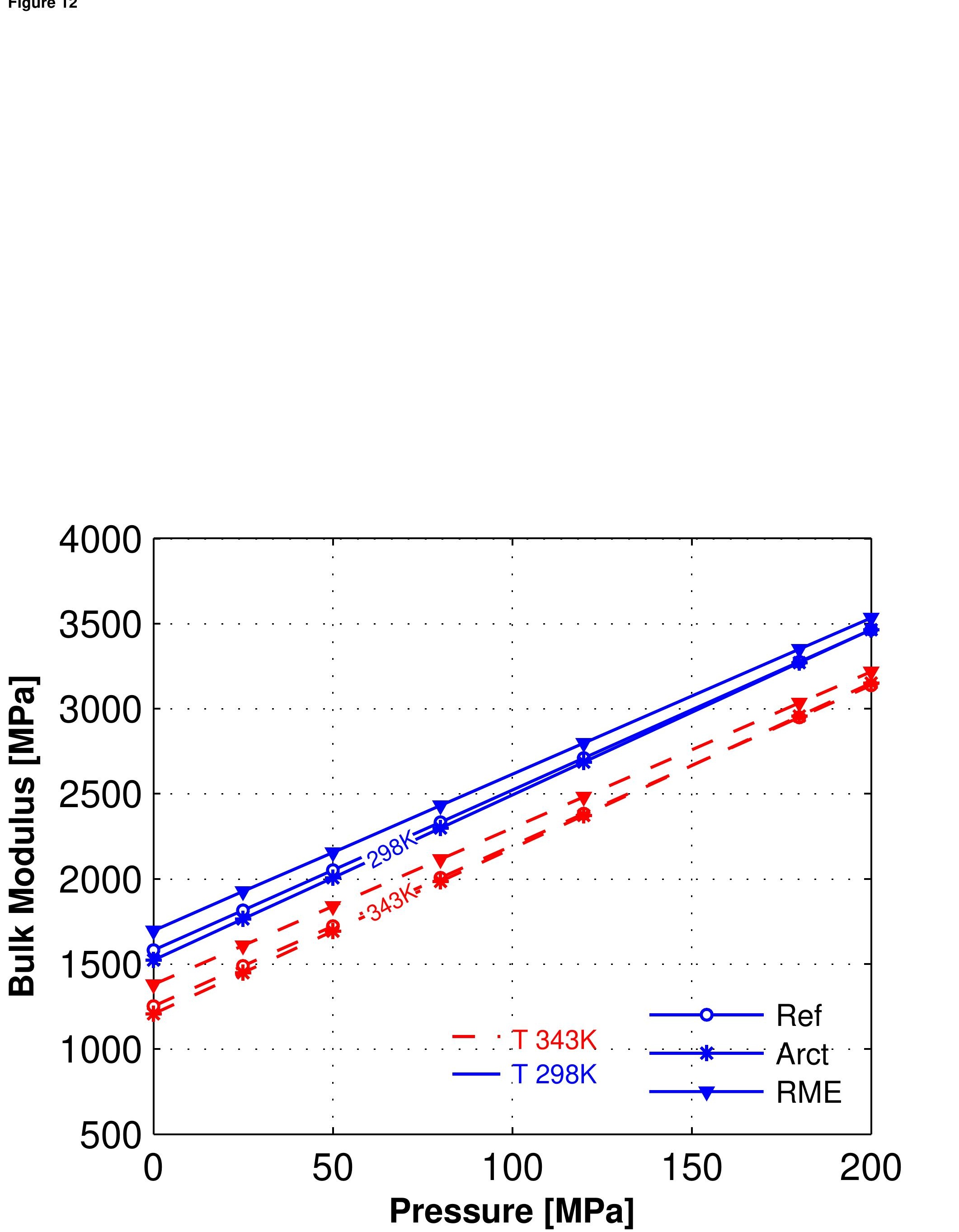
Figure A.1

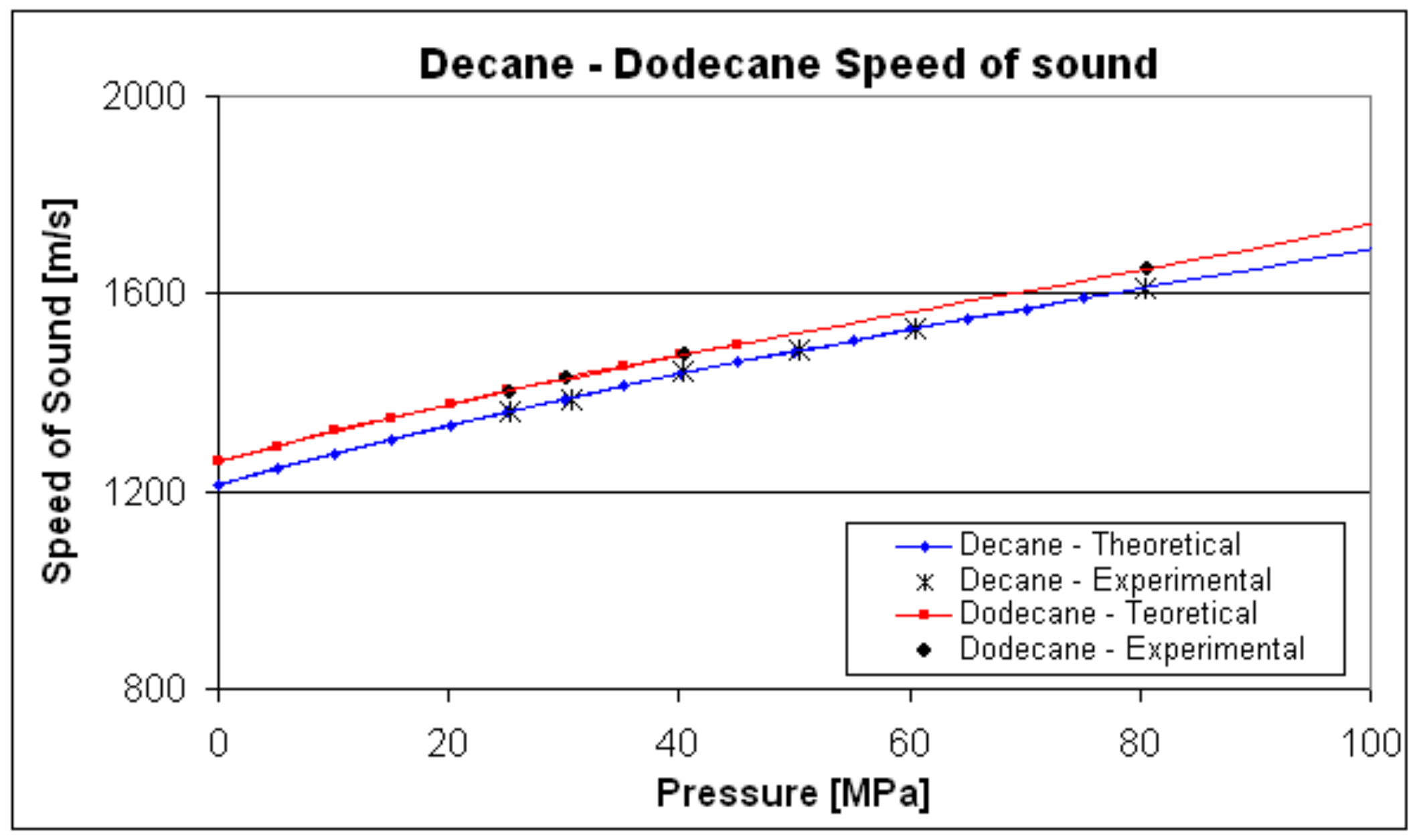




\section{Decane - Dodecane: Density}

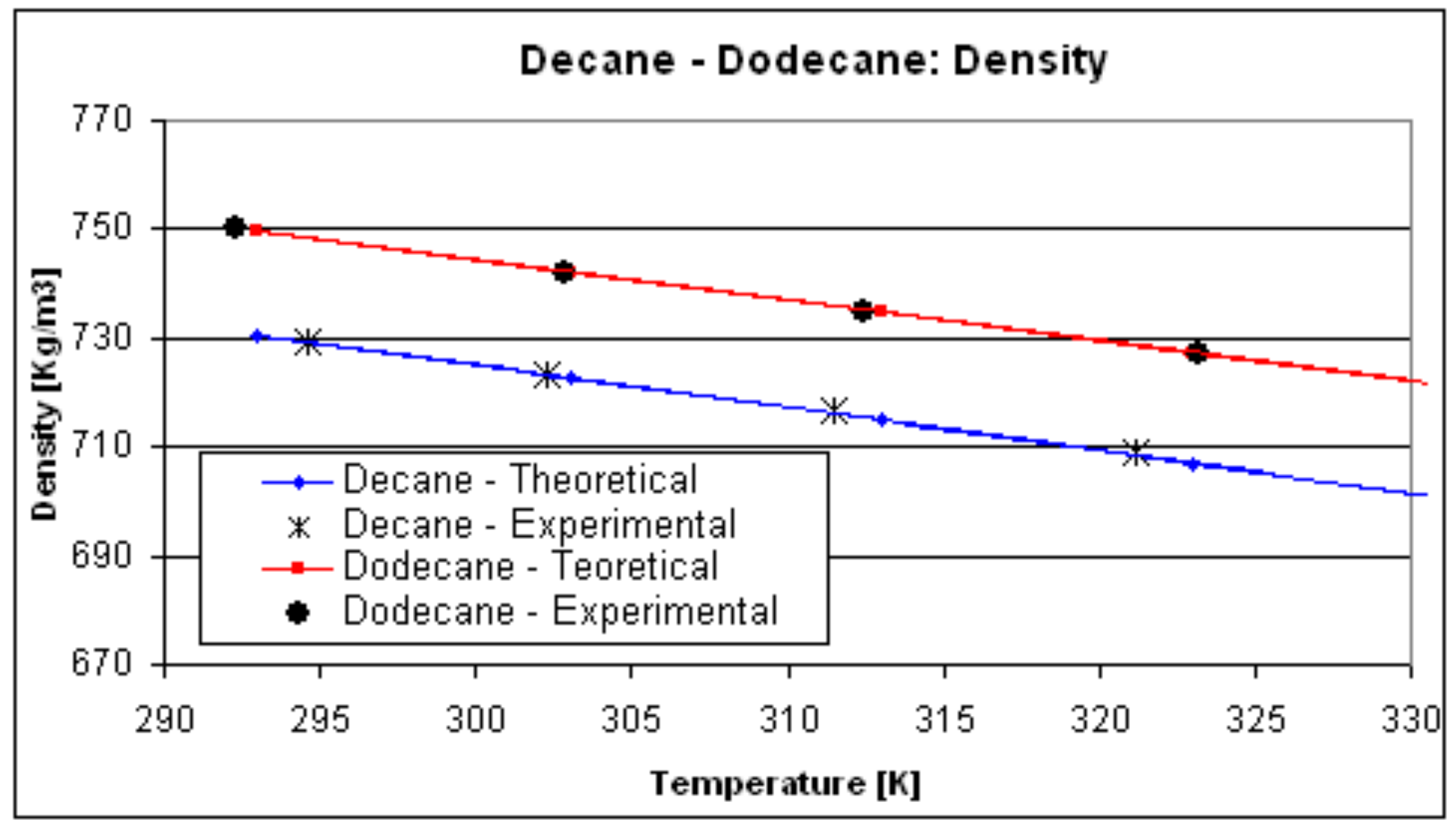

Figure A.2 